\title{
Multi-instrumental approach with archival research to study the Norwich textile industry in the late eighteenth and early nineteenth centuries: the example of a Norwich pattern book dated c. 1790-1793
}

\author{
Jocelyn Alcántara-García ${ }^{1 *}$ (D) and Michael Nix²
}

\begin{abstract}
Merchant-manufacturers in Norwich, a major centre for textile production in England, used pattern books and pattern cards containing swatches of worsted and worsted mixed with other yarns to facilitate sales and trade. Studying such well-preserved and dated materials provides valuable information that can translate into informed decisions for the care of Norwich textile collections. Using a Norwich pattern book from Winterthur Museum's Special Collections dated c. 1790-1793, we report the first stage of a substantial study that combines spectroscopic and chromatographic techniques with archival research. A combination of X-ray fluorescence (XRF), high performance liquid chromatography-photodiode array (HPLC-PDA) and scanning electron microscopy-energy dispersive X-ray spectroscopy (SEM-EDX) allowed for identification of characteristic mordants like iron and tin salts; and dyes, like quercitron, native to North America. In addition, a combination of Fourier transform infrared spectroscopy (FTIR) and gas chromatography-mass spectrometry (GC-MS) allowed for partial identification of the glazed finish in some textiles as a natural gum. Setting the foundations for future conservation and conservation science work, our research contributes to the care of these important and beautiful textiles, by providing scientific evidence for humidity and/or light sensitive constituent materials.
\end{abstract}

Keywords: Norwich stuffs, Natural dyestuffs, Pattern book, Chromatography, SEM-EDX, XRF, FTIR

\section{Introduction}

The significance of the cathedral city of Norwich can be attributed in part to its success as a centre for textile production in the British Isles from at least the fourteenth century until the industry's decline in the nineteenth century. For a long period, Norwich could justifiably claim to be the second wealthiest city in England after London.

Norwich's manufacturers used smooth, strong, silky worsted yarn spun from long-staple combed wool in the counties of East Anglia and, from the early eighteenth

\footnotetext{
*Correspondence: joceag@udel.edu

${ }^{1}$ Department of Art Conservation, University of Delaware, 18 E. Main St. Room 303, Newark, DE 19716, USA

Full list of author information is available at the end of the article
}

century, southern Ireland. Fabrics woven with worsted and worsted mixed with other yarns such as silk were known as 'Norwich stuffs' [1].

During the eighteenth century, Norwich refocused its trading networks by concentrating on foreign rather than domestic markets. Its reach became global. The city's manufacturers sent high quality stuffs direct to overseas merchants and dealers in Europe and North America or through intermediaries in London. They also made large quantities of camblet, a plain weave worsted fabric, for the East India Company's trade in Canton (Guangdong), China and dispatched goods to merchants in Spain and Portugal some of whom also re-exported to the colonial markets in South and Central America. 


\section{Norwich pattern books}

Swatches cut from pieces of cloth mounted in pattern books or on pattern cards provided a point of contact between the manufacturer and the distant buyer who used them to select the fabrics he or she wanted to buy. Organised in numerical sequence, the swatches were essential management tools for the communication of orders. Manufacturers saw such books '... not only as a history of their trade, but as a resource for communicating complex technical information quickly and efficiently. Nothing could supplant the effectiveness of a sample textile to communicate information about a pattern, colour, texture and finish' [2]. As exporters of vast quantities of stuffs, Norwich's manufacturers relied heavily on pattern books and pattern cards in their transactions with foreign and London customers.

When superseded by new patterns, books and cards were retained and incorporated into the manufacturer's business and design archive. Books and cards containing numerous Norwich swatches that survive from these archives date from the latter half of the eighteenth and the early nineteenth centuries. They have proven to be invaluable sources of information and are generally very well preserved. Some are also labelled and dated. Figure 1 shows an example of a pattern book and Fig. 2 its accompanying price list.

Several institutions have small collections of pattern books and pattern cards comprising: the Norwich Castle Study Centre and Victoria \& Albert Museum (United
Kingdom); Winterthur Museum, Garden and Library (United States); Nordiska Museet (Sweden); Bibliothèque Forney (France); and Fries Museum (Netherlands). The Winterthur Library houses six Norwich pattern books which date between $c .1786$ and $c .1809$ [3]. Altogether they contain about 8,000 swatches, most of them very well preserved.

\section{The Norwich dyeing industry}

During the mid-eighteenth century, Norwich and London were pre-eminent in the dyeing industry: the two centres dyed and finished most of the fine worsted goods produced in the country. John James, an historian of the English worsted industry, attributed a 'beauty and permanence' to Norwich dyes, so much so that manufacturers from all over England chose to send their stuffs to the city [4].

Detailed knowledge about the work of Norwich's dyers, their labour vital in transforming materials from plain, pattern- and colourless fabrics, into desirable consumer products, is virtually unknown. Mellor and Cardwell note that dyeing was 'a highly individual technique and secrecy was a necessary part of the Art' [5]. During his visit to Norwich in 1784, the Frenchman Maximilien de Lazowski complained: "We haven't seen a dye-house, although I have asked several times to do so. They are extremely jealous in guarding their processes" [6].

By keeping secret his technique of dyeing bombazine (a mixture of worsted and silk) a beautiful black, the
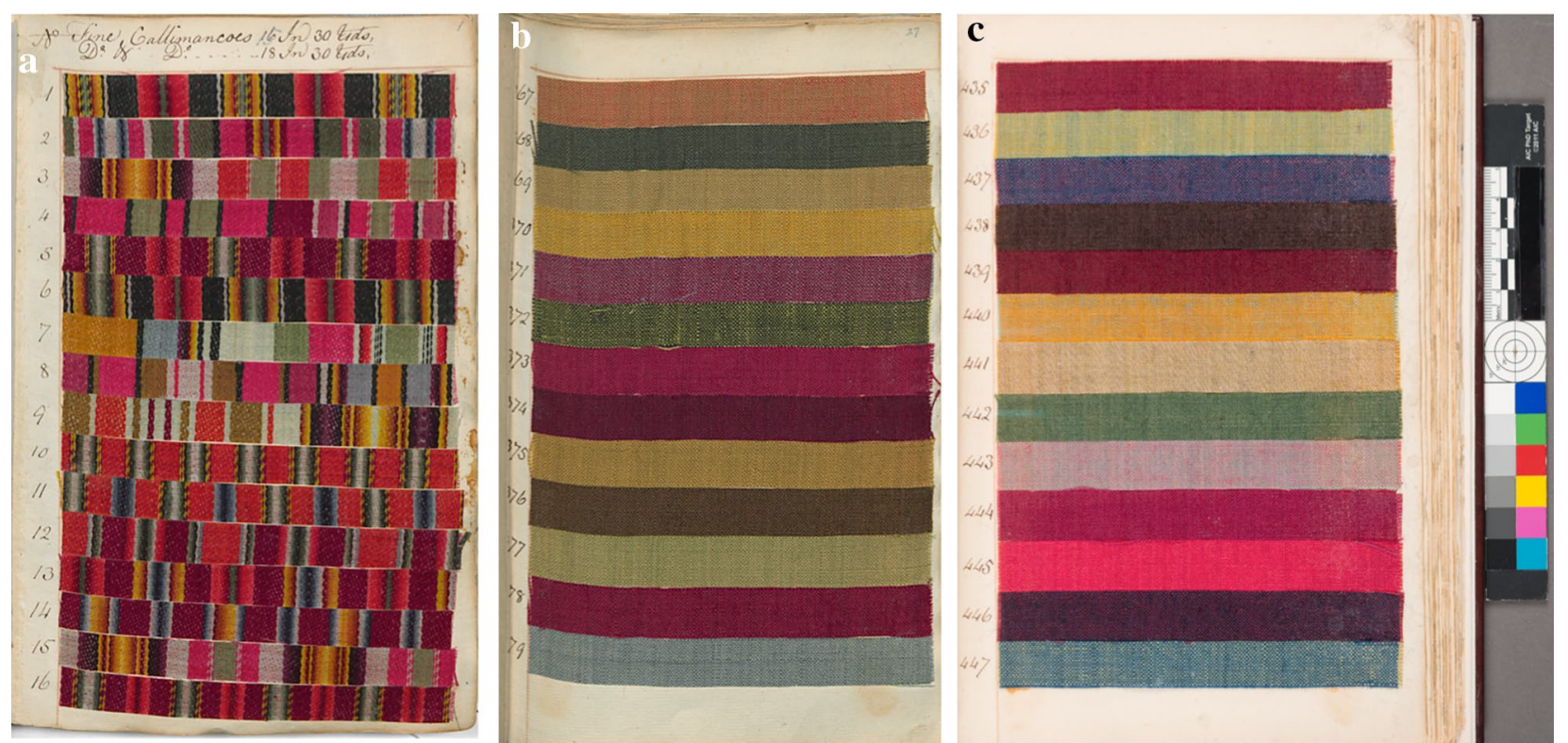

Fig. 1 Norwich worsted pattern book (c. 1790-1793), accession number $65 \times$ 695.3. a page 1, b page 27, c page 32. Winterthur Museum, Garden and Library 


\begin{tabular}{|c|c|c|c|c|c|c|c|}
\hline \multirow{9}{*}{ 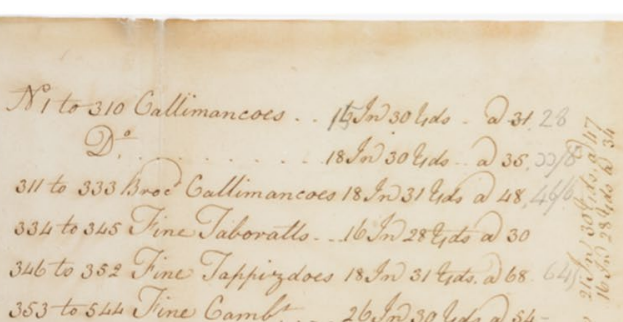 } & \multirow{2}{*}{$\frac{\text { Pattern No. }}{\text { No. } 1 \text { to } 310}$} & \multicolumn{2}{|l|}{ Fabric } & $\begin{array}{l}\text { Width } \\
\text { (Inches) }\end{array}$ & $\begin{array}{l}\text { Length } \\
\text { (Yards) }\end{array}$ & \multicolumn{2}{|c|}{$\begin{array}{l}\text { Price in shillings } \\
\& \text { pence }\end{array}$} \\
\hline & & Callimancoes & & 16 In & $30 \mathrm{Yds}$ & (a) 31 & 28 \\
\hline & & $\mathrm{D}[\mathrm{itt}] \mathrm{o}$ & & $18 \mathrm{In}$ & $30 \mathrm{Yds}$ & (a) 35 & $33 / 6$ \\
\hline & 311 to 333 & Broc[aded] & & $18 \mathrm{In}$ & $30 \mathrm{Yds}$ & (a) 48 & $46 / 6$ \\
\hline & & Callimancoes & & & & & \\
\hline & 334 to 345 & Fine Taboratts & & 16 In & $31 \mathrm{Yds}$ & (a) 30 & \\
\hline & 346 to 352 & Fine Tappizadoes & & $18 \mathrm{In}$ & $31 \mathrm{Yds}$ & @ 68 & $64 /-$ \\
\hline & 353 to 544 & Fine $\mathrm{Camb}[\mathrm{le}] \mathrm{t}[\mathrm{s}]$ & & 26 In & $30 \mathrm{Yds}$ & (a) 54- & \\
\hline & 545 to 586 & Cheque Cam[let]ee[s] & & $16 \mathrm{In}$ & $28 \mathrm{Yds}$ & (a) 22 & \\
\hline 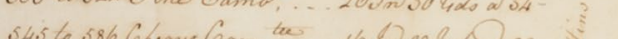 & 587 to 594 & Spotted Cam[let]ee[s] & & 16 In & $28 \mathrm{Yds}$ & (a) 25 & \\
\hline 043203866 heque 6 am ... 16.9228400 a 22 & 595 to 600 & Fine Battavias & & $16 \mathrm{In}$ & $28 \mathrm{Yds}$ & (a) 34 & \\
\hline 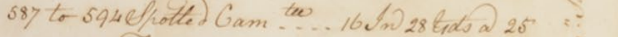 & 601 & Sup [e]r Fine Lastings & & $21 \mathrm{In}$ & $30 \mathrm{Yds}$ & (a) 100 & \\
\hline 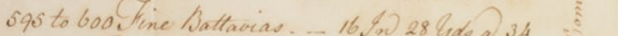 & 602 & $\mathrm{D}[\mathrm{itt}] \mathrm{o}$ & & $21 \mathrm{In}$ & $30 \mathrm{Yds}$ & @ 95 & \\
\hline borelustine pation & $603-607$ & $\mathrm{D}[\mathrm{itt}] \mathrm{o}$ & & $21 \mathrm{In}$ & $30 \mathrm{Yds}$ & (a) 90 & \\
\hline he & 608 & $\mathrm{D}[\mathrm{itt}] \mathrm{o}$ & & 21 In & $30 \mathrm{Yds}$ & (a) 85 & \\
\hline$\cdots \quad 214030$ Ldo ad 95 & 609 & $\mathrm{D}[\mathrm{itt}] \mathrm{o}$. & & $21 \mathrm{In}$ & $30 \mathrm{Yds}$ & @ 80 & \\
\hline $603660 \% .90$ & 610 & $\mathrm{D}[\mathrm{itt}] \mathrm{o}$ & & $21 \mathrm{In}$ & $30 \mathrm{Yds}$ & (a) 75 & \\
\hline $608 \ldots 9$ & 611 & $\mathrm{D}[\mathrm{itt}] \mathrm{o}$ & & $21 \mathrm{In}$ & $30 \mathrm{Yds}$ & (@) 70 & \\
\hline 30 ldo ad 85 & 612 & $\mathrm{D}[\mathrm{itt}] \mathrm{o}$ & & 21 In & $30 \mathrm{Yds}$ & (a) 65 & \\
\hline - Tron volidar. & 613 to 629 & Cam[let]s & \{ & $27 \mathrm{In}$ & $30 \mathrm{Yds}$ & (@) 70 & \\
\hline 610. & & $\mathrm{D}[\mathrm{itt}] \mathrm{o}$ & \{ & $21 \mathrm{In}$ & $30 \mathrm{Yds}$ & @ 54 & \\
\hline $63080=70$ & $630-645$ & $\mathrm{D}[\mathrm{itt}] \mathrm{o}$ & \{ & 27 In & $30 \mathrm{Yds}$ & (a) 67 & \\
\hline Wo zido al 70 & & & \{ & $21 \mathrm{In}$ & $30 \mathrm{Yds}$ & (a) 52 & \\
\hline trdo of 65 & 646 to 660 & $\mathrm{D}[\mathrm{itt}] \mathrm{o}$. & \{ & 27 In & $30 \mathrm{Yds}$ & (a) $63 / 6$ & \\
\hline 630 tobis. & & & \{ & $21 \mathrm{In}$ & $30 \mathrm{Yds}$ & (a) 49 & \\
\hline 64666660 of $\quad\left\{\begin{array}{l}37 \\
213\end{array} 30\right.$ hd a by & 661 to 674 & & \{ & 27 In & $30 \mathrm{Yds}$ & (a) 61 & \\
\hline 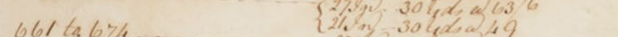 & & & \{ & 21 In & $30 \mathrm{Yds}$ & @ 47 & \\
\hline 27,03045204 & No. 675 to 685 & Com[mo]n Sattins & & $21 \mathrm{In}$ & $30 \mathrm{Yds}$ & (a) 47 & \\
\hline & & & & 16 In & $28 \mathrm{Yds}$ & (a),34 & \\
\hline
\end{tabular}

Fig. 2 Price list associated with Norwich worsted pattern book (c. 1790-1793), accession number $65 \times$ 695.3. and transcript. Winterthur Museum, Garden and Library

innovative Norwich dyer and chemist Michael Stark, cornered the market; his dyeworks received most of this fabric produced in the city, in Kidderminster and in Yorkshire. Dyers such as Stark, in order to match colours precisely to meet consumer requirements, kept pattern books containing recipes and samples of colours [7]. Yet, even though Norwich was a major centre of dyeing, no master dyer recipe books, as far as it is known, survive from the period under review.

While Norwich's textiles flowed outwards on a global scale, organic and inorganic dyestuffs came into the city from many parts of the world as well from Britain. To our knowledge no in-depth research has been carried out into the city's role in this trade. Globally, eighteenth century dyers had access to about thirty dyestuffs and fifteen mordants [8].

\section{The study of a Norwich worsted pattern book as a first approach (c. 1790-1793)}

Without extensive records of Norwich's dyeing practices, it is to our advantage to gain and provide solid scientific evidence that assists with the care and preservation of Norwich textiles found in collections in Europe and North America. Evidence derived from our archival and scientific findings will also aid our understanding of manufacturing processes and the national and international trade in dyestuffs.

Despite the importance of the pattern books and pattern cards, the present work is, to the best of our knowledge, the first substantial scientific research ever conducted on Norwich textiles other than: an independent study by Beth Szuhay (on textile finishes) [9]; analysis of an undated Norwich wool textile from the Winterthur collection, where indigo carmine, madder and weld were identified [10]; two small investigations into a dye known as 'Norwich red'; and a piece of green fabric from an eighteenth century wing chair analysed by the Institut Royale du Patrimoine Artistique in Brussels during 2016. Based on a conversation with C. Terry (Senior Curator Senior Curator of Social History, Norfolk Museums Service), the Belgian study found evidence of an indigoid dye.

Using a combination of scientific and historical research, we commenced a comprehensive and comparatively large-scale study of dyestuffs used in Norwich, starting with 47 samples of numbered patterns in a dated Norwich worsted pattern book (accession no. $65 \times 695.3$ ) in the Downs Collection of Manuscripts and Ephemera in the Winterthur Library collection (Fig. 1). The book 
is attributed to J. Tuthill \& Son(s) whose manufactory was located in the parish of St. George Colegate, Norwich (see $65 \times 695.3$ in [3]). Chosen for study because of its pristine condition, it contains 685 swatches grouped and named by fabric type with dimensions of completed pieces in inches and yards. Fabrics are of numerous patterns, including 333 swatches of fine and fine brocaded callimancoes, 62 camblets, 12 fine flowered taborets (shaded and often striped worsted fabric) and a two of hard-wearing superfine lastings (everlastings). It also contains two price lists, one of which is associated with the book (Fig. 2). An almost identical book exists in the Norwich collection (see Norwich pattern book NWHCM 1953.76, Norfolk Museums Service) [11].

\section{Experimental procedures}

Understanding the implications of sampling Tuthills' well-preserved Norwich pattern book, we commenced our project with four long-term goals in mind: Firstly, to add to the existing body of knowledge concerning Norwich dyes and dyers; secondly, to increase our understanding of materials and techniques used in the Norwich dyeing industry during the late eighteenth and early nineteenth centuries; thirdly, to understand the materials used in the making of stuffs within an historic context as a means of ensuring their preservation; and lastly, to assist in choosing appropriate treatments and provide evidence for preventing or slowing down future changes that may lead to permanent damage, i.e. photo sensitive dyes [12-14]. For the purpose of this paper: a swatch comprises a small, rectangular piece cut from a length of woven fabric; a pattern consists of a swatch with its associated running number; and a sample is a single thread removed from a swatch for analytical purposes.

Two criteria provided the basis for selecting the pages for study: [1] the wide variety of colours and, wherever possible, [2] the presence of loose threads to minimise the invasiveness of sampling (all are weft). Initially choosing three pages, we began our dye analysis using samples from pages 1 (patterns 1-16, Fig. 1a), 27 (367-379, Fig. 1b), and 32 (435-447, Fig. 1c), the last two featuring fine single camblets, a fabric extensively manufactured in Norwich. We also pursued the identification of a characteristic glazed surface coating on the sixteen striped, fine callimancoes featured on page 1 , as well as the adhesive used to stick down the swatches.

It is worth pointing out that unlike other textiles that survive, swatches in the Norwich books are post-production items, were not worn or washed, and rarely exposed to light. Except for possible grime from handling, they can be considered as 'unused. Here, we present the first substantial scientific analysis of Norwich stuffs, using a combination of chromatographic, spectroscopic and microscopic techniques.

Detailed information for all spectroscopic methods and instrumentation, as well as liquid chromatography and recovery of dyes can be found in Additional file 1 .

\section{X-ray fluorescence (XRF)}

Non-destructive, qualitative energy-dispersive $\mathrm{X}$-ray fluorescence (ED-XRF) spectroscopy was performed to determine the sample area's elemental composition to infer possible mordants. Analysis was performed with a Bruker ARTAX $\mu$ XRF spectrometer using a rhodium tube.

\section{High performance liquid chromatography- photodiode-array detector (HPLC-PDA)}

HPLC was carried out using a Varian 460-LC instrument, including a Varian 410 autosampler, two Varian 212 solvent delivery modules, high-pressure mixer, vacuum degasser, and a Varian Prostar 335 Photodiode array (PDA) detector. The analytical column was a Phenomenex Luna ${ }^{\circledR} 3 \mu \mathrm{m}$ C18 [2] column $(2.0 \times 100 \mathrm{~mm}$, end capped). Separation program was adapted from the Ref. [14] using solution A (10\% methanol, $90 \%$ aqueous solution of $1 \%$ formic acid) and B (90\% methanol, 10\% aqueous solution of $1 \%$ formic acid). Injection volumes were $20 \mu \mathrm{L}$. Identification of dye components was performed using retention times $\left(t_{R}\right)$ and $U V-V i s$ spectra of known references and spectra kindly shared by Dr. Jan Wouters.

\section{Recovery of dyes}

A mild acid hydrolysis recovery method (OA: oxalic acid) was used for all samples unless otherwise stated. The OA hydrolysis solution was a mixture of methanol/acetone/ water/0.21 $\mathrm{M}$ aqueous oxalic acid (30:30:40:1, v/v/v/v) according to [14], using approximately $1 \mathrm{~cm}$ of fibre from each textile sample.

In cases where no dye components were detected, samples were further hydrolysed using the harsh hydrolysis method reported in the work of [15], using a solution of $37 \% \mathrm{HCl} / \mathrm{HPLC}$-grade methanol/MilliQ ${ }^{\circledR}$ type 1 water.

\section{Micro-Fourier transform infrared spectroscopy ( $\mu$-FTIR)}

Sample material for glaze analysis was recovered by first soaking approximately $1 \mathrm{~cm}$ of coated fabric sample in $100 \mu \mathrm{L}$ of deionized water for $48 \mathrm{~h}$, decanting the solvent and drying it out for FTIR spectroscopic analysis. The supernatant was placed on a well glass slide and dried on a hot plate at $40{ }^{\circ} \mathrm{C}$, then subsequently scraped off and placed directly onto a diamond cell. The material was rolled flat on the cell with a stainless steel micro-roller. After air-drying, a second 48-h wash was carried out on the same sample using $100 \mu \mathrm{L}$ 
of chloroform to extract any non-polar component of the coating material. Solvent again was decanted and dried out for FTIR analysis. No non-polar substances seemed to be extracted with the chloroform. Dry fibre was used for further HPLC-PDA analysis. This procedure allowed us to gain information for both glazing material and dyes, greatly reducing the overall sampling of the book, while maximizing information gained. Thread samples were taken from swatches on page 1 (Fig. 1a).

Yellowed adhesive used to stick down the swatches was removed mechanically from areas in which a swatch had partially detached. Samples were analysed using a Thermo Scientific Nicolet 6700 FTIR with Nicolet Continu m FTIR microscope (transmission mode).

\section{Gas chromatography-mass spectrometry (GC-MS)}

Preliminary FTIR analysis of the glaze suggested the presence of gums. We consolidated all 16 samples extracted with water from page 1 and ran the analysis using our standard method for carbohydrates (gums, starch, sugars, cellulose). The sample, analysed for carbohydrate content was treated with approximately $100 \mu \mathrm{L}$ of a $0.5 \mathrm{M}$ solution of $\mathrm{HCl}$ (Fisher Scientific) in methanol at $70{ }^{\circ} \mathrm{C}$ for $24 \mathrm{~h}$ in a tightly capped, heavywalled GC vial. The $0.5 \mathrm{M} \mathrm{HCl} /$ methanol (Optima ${ }^{\text {TM }}$ LC/MS grade, Fisher Chemical) solution was prepared fresh for the day's work (unstable in 3-4 days) by adding $400 \mu \mathrm{L}$ of anhydrous acetyl chloride $(+99 \%$. ACROS Organics $^{\mathrm{TM}}$ ) to $15 \mathrm{~mL}$ of anhydrous methanol (99.93\%, Aldrich, ACS reagent) and stirring. The digested sample solutions were evaporated to dryness in a stream of air and then treated with $50-100 \mu \mathrm{L}$ of BSTFA $(N, O$-bis (trimethylsilyl) trifluoroacetamide) with 1\% TMCS (trimethylchlorosilane) (Grace reagent, packaged in $1 \mathrm{~mL}$ glass ampoules) and heated at $70{ }^{\circ} \mathrm{C}$ for one hour.

The sample was analysed using the Agilent Technologies 7820 gas chromatogram equipped with Agilent 5973 mass selective detector (MSD) and an automatic liquid injector. A sample volume (splitless) of $1 \mu \mathrm{L}$ was injected onto a $30 \mathrm{~m} \times 250 \mu \mathrm{m} \times 0.25 \mu \mathrm{m}$ film thickness HP-5MS column (5\% phenyl methyl siloxane at a flow rate of $1.5 \mathrm{~mL} / \mathrm{min}$ ). The Agilent Technologies G1701EA GC/MSD ChemStation Control software was used with conditions as follows: inlet temperature was $320{ }^{\circ} \mathrm{C}$ (splitless mode) with a 9 min solvent delay. The $\mathrm{GC}$ oven temperature program was $55^{\circ} \mathrm{C}$ for $1.25 \mathrm{~min}$, then ramped at $50{ }^{\circ} \mathrm{C} / \mathrm{min}$ to $150{ }^{\circ} \mathrm{C}$, then ramped at $2{ }^{\circ} \mathrm{C} / \mathrm{min}$ to $200{ }^{\circ} \mathrm{C}$, then ramped at $20^{\circ} \mathrm{C} / \mathrm{min}$ to $300^{\circ} \mathrm{C}$ followed by a $5 \mathrm{~min}$ isothermal period. The transfer line temperature to the MSD (SCAN mode) was $280^{\circ} \mathrm{C}$, the source at $230{ }^{\circ} \mathrm{C}$ and the MS quad at $150^{\circ} \mathrm{C}$.

\section{Scanning electron microscopy-energy dispersive X-ray} spectroscopy (SEM-EDX)

A fragment of the thread collected from pattern 447 was adhered to an aluminium slot head SEM stub using double-sided carbon tab. The sample was carbon-coated to prevent charging, and then examined using a Zeiss EVO MA15 scanning electron microscope with $\mathrm{LaB}_{6}$ source.

\section{Results and discussion}

High performance liquid chromatography-photodiode array detector (HPLC-PDA) and X-ray fluorescence (XRF) results are displayed in Table 1 , divided by colour and pattern number.

Methods such as gas chromatography-mass spectrometry (GC-MS) [12, 16], voltammetry, [17] nonand minimally invasive techniques such as fibre optic reflectance spectroscopy (FORS) $[18,19]$ and in situ surface enhanced Raman spectroscopy (SERS) [20-22] have proven useful for the study of historically relevant natural dyes. However, the most reliable identification method remains high performance liquid chromatography (HPLC) [14, 23-25]. Using a photodiode array detector (PDA), HPLC has successfully provided information about dye components, even when using samples in which dye concentration is as low as a few nanograms [24]. To fulfil our aims with the purpose of informing both conservators and historians, we used this chromatographic method with a combination of spectroscopies to obtain the maximum information about the dyestuffs contained in samples which, because of the intrusive nature of the sampling process, are necessarily restricted in number and length.

Without contemporary Norwich recipe books to inform our research, recourse was made to advertisements of bankrupt and other stock in local newspapers between 1817 and 1837 to help establish historically the kinds of mordants, dyes and chemicals available to the city's dyers [26, 27]. We related this research to our scientific findings. Although these advertisements post-date the pattern book being studied, they nevertheless fall within the period under review. We took into account that dyeing did not go through any major transformation until the advent of aniline dyes in 1856 and assumed a continuity in the use of traditional products stretching back decades for dyes such as quercitron, and centuries for dyes such as madder [28].

\section{Mordants}

Newspaper advertisements refer to mordants such as alum (potassium aluminium sulphate), verdigris (copper acetates), copperas or green/blue vitriol (possibly iron and/or copper sulphate), cream of tartar (potassium 
Table 1 Experimental results of samples taken from pages 1, 27 and 32 of Norwich worsted pattern book (c. 1790-1793), accession number 65 × 695.3. Winterthur Museum, Garden and Library

\begin{tabular}{|c|c|c|c|c|c|}
\hline Colour & $\begin{array}{l}\text { Sample } \\
\text { number* }\end{array}$ & Page & Dye components ${ }^{a}$ & Possible & XRF results ${ }^{b}$ \\
\hline Paper & N/A & $1,27,32$ & N/A & N/A & $\mathrm{Fe}, \mathrm{Co}, \mathrm{K}, \mathrm{Ca}, \mathrm{As}$ \\
\hline \multirow[t]{3}{*}{ Pink } & $1^{*}$ & 1 & car, pur & Cochineal, madder & $\mathrm{Sn}, \mathrm{Cu}, \mathrm{Ca}, \mathrm{Zn}, \mathrm{S}, \mathrm{Fe}, \mathrm{K}$ \\
\hline & $15^{*}$ & 1 & car, dcll & Cochineal & $\mathrm{Sn}, \mathrm{Ca}, \mathrm{Fe}$ \\
\hline & 443 & 32 & car & Cochineal & $\mathrm{Sn}, \mathrm{Ca}$ \\
\hline \multirow[t]{6}{*}{ Red } & $3^{*}$ & 1 & ali,' car, pur, ppur & Madder, cochineal & $\mathrm{Sn}, \mathrm{Ca}, \mathrm{Zn}, \mathrm{Cu}, \mathrm{S}, \mathrm{Fe}$ \\
\hline & $10^{*}$ & 1 & ali, fka, car, pur & Madder, cochineal & $\mathrm{Ca}, \mathrm{Sn}$ \\
\hline & 367 & 27 & car, fka & Cochineal & $\mathrm{Cu}$ \\
\hline & 445 & 32 & car, dcll & Cochineal & $\mathrm{Sn}, \mathrm{Ca}, \mathrm{Fe}, \mathrm{Ti}$ \\
\hline & $11^{*}$ & 1 & lut', api', lut, api & Weld & $\mathrm{Fe}, \mathrm{Sn}$ \\
\hline & 370 & 27 & lut, api & Weld & $\mathrm{Fe}, \mathrm{Co}, \mathrm{K}, \mathrm{Ca}$, As \\
\hline \multirow[t]{3}{*}{ Yellow } & 372 & 27 & lut, api & Weld & $\mathrm{Fe}, \mathrm{Co}, \mathrm{K}, \mathrm{Ca}$, As \\
\hline & 436 & 32 & lut, api & Weld & $\mathrm{Fe} \approx \mathrm{Cu}$ \\
\hline & 447 & 32 & mor, rut & Old fustic & $\mathrm{Ca}$ \\
\hline \multirow[t]{3}{*}{ Orange } & $7^{*}$ & 1 & ea, fis, sul, lut', api' & Tannin source, young fustic, weld & $\mathrm{Ca}, \mathrm{Fe}$ \\
\hline & 440 & 32 & fis, sul, lut', api', quer & Young fustic, weld, quercitron & $\mathrm{Ca}, \mathrm{Fe}$ \\
\hline & $4^{*}$ & 1 & orc, in & Orchil, indigo plant & $\mathrm{Ca} \approx \mathrm{Fe}, \mathrm{S}, \mathrm{Cu}, \mathrm{Zn}$ \\
\hline \multirow[t]{10}{*}{ Purple } & $5^{*}$ & 1 & orc & Orchil & $\mathrm{Sn}, \mathrm{Zn}, \mathrm{Cu}, \mathrm{K}, \mathrm{Ni}, \mathrm{S}, \mathrm{Fe} \approx \mathrm{Ca}$ \\
\hline & $14^{*}$ & 1 & orc & Orchil & $\mathrm{Zn}$ \\
\hline & $16^{*}$ & 1 & orc & Orchil & $\mathrm{Ca}, \mathrm{Zn}$ \\
\hline & 374 & 27 & No dye components detected & & \\
\hline & 378 & 27 & orc & Orchil & $\mathrm{Zn}, \mathrm{Ca}$ \\
\hline & 435 & 32 & orchil, mor, in & Orchil, indigo plant, old fustic & $\mathrm{Fe}, \mathrm{Ca}, \mathrm{Zn}$ \\
\hline & 437 & 32 & orc, in & Orchil, indigo plant & $\mathrm{Fe}, \mathrm{Cu}, \mathrm{Ca}, \mathrm{Zn}$ \\
\hline & 439 & 32 & No dye components detected & & $\mathrm{Fe}, \mathrm{Ca}, \mathrm{Zn}, \mathrm{Cu}$ \\
\hline & 444 & 32 & orc & Orchil & $\mathrm{Fe}, \mathrm{Ca}, \mathrm{Zn}, \mathrm{Cu}$ \\
\hline & 446 & 32 & orc, in & Orchil, indigo plant & $\mathrm{Zn}, \mathrm{Fe}$ \\
\hline \multirow[t]{3}{*}{ Brown } & $9^{*}$ & 1 & quer, in & Quercitron oak, indigo plant & $\mathrm{Fe}, \mathrm{Co}, \mathrm{K}, \mathrm{Ca}, \mathrm{As}$ \\
\hline & 376 & 27 & orc, ea & Tannin source, orchil & $\mathrm{Cu}$ \\
\hline & 438 & 32 & ea & Tannin source & $\mathrm{Fe}, \mathrm{Cu}$ \\
\hline \multirow[t]{8}{*}{ Blue } & $8^{*}$ & 1 & in & Indigo plant & $\mathrm{Fe}, \mathrm{Cu}, \mathrm{As}$ \\
\hline & $13^{*}$ & 1 & in & Indigo plant & $\mathrm{Fe}$ \\
\hline & 371 & 27 & in, orc & Indigo plant, orchil & $\mathrm{Ca}, \mathrm{Zn}, \mathrm{Cu}$ \\
\hline & 379 & 27 & in & Indigo plant & $\mathrm{Cu}, \mathrm{Zn}, \mathrm{Fe}, \mathrm{Ca}$ \\
\hline & 437 & 32 & in & Indigo plant & $\mathrm{Cu}, \mathrm{Fe}$ \\
\hline & 443 & 32 & No dye components detected & & $\mathrm{Fe}, \mathrm{Ca}, \mathrm{Cu}$ \\
\hline & 446 & 32 & in, orc & Indigo plant, orchil & $\mathrm{Fe}, \mathrm{Ca}, \mathrm{Cu}$ \\
\hline & 447 & 32 & in & Indigo plant & $\mathrm{Fe}, \mathrm{Ca}, \mathrm{Zn}$ \\
\hline \multirow[t]{6}{*}{ Light Blue } & 436 & 32 & in, ir & Indigo & \\
\hline & 440 & 32 & in, ir & Indigo & $\mathrm{Cu}$ \\
\hline & $2^{*}$ & 1 & ea, quer, in & Quercitron oak, tannin source, indigo plant & $\mathrm{Cu}$ \\
\hline & $6^{*}$ & 1 & in & Indigo plant, no yellow components detected & $\mathrm{Fe}, \mathrm{Ca}, \mathrm{Cu}, \mathrm{S}$ \\
\hline & $12^{*}$ & 1 & quer, in & Quercitron oak, tannin source, indigo plant & $\mathrm{Fe}$ \\
\hline & 367 & 27 & ea, mor & Tannin source, old fustic & $\mathrm{Fe}, \mathrm{Ca}, \mathrm{Cu}, \mathrm{S}$ \\
\hline
\end{tabular}


Table 1 (continued)

\begin{tabular}{|c|c|c|c|c|c|c|}
\hline Colour & $\begin{array}{l}\text { Sample } \\
\text { number* }\end{array}$ & Page & & Dye components ${ }^{a}$ & Possible & XRF results ${ }^{b}$ \\
\hline \multirow[t]{5}{*}{ Green } & 368 & & 27 & ea, mor' & Tannin source, old fustic & $\mathrm{Fe}, \mathrm{Cu}$ \\
\hline & 370 & & 27 & ea, mor, in & Tannin source, old fustic, indigo plant & $\mathrm{Fe}, \mathrm{Cu}$ \\
\hline & 372 & & 27 & No dye components detected & & $\mathrm{Ca}, \mathrm{Fe}, \mathrm{Cu}$ \\
\hline & 377 & & 27 & quer, in, mor' & Quercitron oak, indigo plant, old fustic & $\mathrm{Fe}$ \\
\hline & 442 & & 32 & & in Indigo plant & $\mathrm{Fe} \approx \mathrm{Cu}$ \\
\hline
\end{tabular}

Winterthur Museum, Garden and Library

*An asterisk next to the sample number indicates textile is glazed; italics denote a weft thread sample

a In-indigotin; ir-indirubin; quer-quercetin; rut-rutin; lut-luteolin; api-apigenin; mor-morin; fis-fisetin; sul-sulfuretin; ali-alizarin; pur-purpurin; ppur-pseudopurpurin; fka-flavokermesic acid; car-carminic acid; dcll-unidentified anthraquinoid compound present in coccid dyes [15]; orc-orcein; ea-ellagic acid, ('indicates the corresponding glucoside)

b All samples showed Fe, Co, K, Ca and As. Major element X-ray lines are listed

bitartrate, $\mathrm{KC}_{4} \mathrm{H}_{5} \mathrm{O}_{6}$ ), arsenic, and granulated tin (possibly tin chloride). Edmonds, like the adverts, also mentions essential cleaning and bleaching materials comprising alkali such as soft soap, soda and pearl ashes, and acids such as sulphuric acid [8].

Quantitative information about inorganic mordants has been provided by the very precise inductively coupled plasma-mass spectrometry or ICP-MS [29]. Scanning electron microscopy-energy dispersive X-ray spectroscopy or SEM-EDX, has likewise yielded reliable data where even mordant distribution can be observed [30, 31].

Since our interest in mordants was more qualitative, rather than quantitative, we chose to use X-ray fluorescence (XRF) which, unlike ICP-MS, provided us with XRF spectra which we subsequently associated with metallic mordants reportedly used during the eighteenth century [32, 33]. In addition, our SEM-EDX instrument required carbon-coating the textile samples to avoid charging of non-conductive materials, which would render difficult further analysis of dyes through HPLCPDA-MS, our main area of interest. Even though the spatial resolution of SEM-EDX is higher than XRF, the latter allowed us to successfully analyse all samples reliably and efficiently. We, however, performed SEM-EDX analysis of one larger sample, a yellow from pattern 447 (Fig. 3), which will be discussed later. Detection of organic mordants such as tannins, like ellagic acid and other plantrelated compounds, was achieved by using HPLC-PDA.

XRF showed the presence of potassium, calcium, iron, cobalt, and arsenic in all samples, including the book's paper. Hence, arsenic detected in all textiles is more likely related to the book's fumigation at some point, rather than the use of sulphuret of arsenic, or orpiment, used as mordant [34]. Cobalt and (partially) potassium can be related to smalt, a potassium cobalt-containing glass pigment, which could be used as an optical brightener in paper [35]. Relative ratios of these elements were different amongst fabrics. In general, relatively higher quantities of iron were present in two of the three brown samples; relatively higher ratios of copper in most of the greens; relatively higher ratios of calcium and tin in pinks and reds; and relatively higher ratios of zinc in purples.

The presence of tin is associated with tin chloride. Tin mordants were used as tin (II) chloride and were often utilised to obtain bright red and yellow colours. Partridge explains the method of making tin liquors using the best aqua-fortis (nitric acid) to dye scarlet and other colours uniformly brilliant [36]. Likewise, Cardon refers to its use with cochineal to enhance scarlet and to one eighteenth century French dyer who achieved cherry, rose, and other red hues by using 'tin liquor', cochineal and 'tartar' [34].

Copper and iron can be related to copperas, either to blue (copper sulphate) or green (iron sulphate), or a mixture of both [37]. When used as mordants, these salts darkened colours. While iron in particular reacted with tannins present in the dye plant, copper usually added as copper sulphate or copper acetate could change colours such as yellow to duller olive tones [32]. It is possible, too, that the copper or iron vats in which dyeing occurred influenced the mordanting process, or the water sources themselves.

Zinc compounds have also been used as mordants, although not as often as the previously mentioned metallic salts. Gardner notes its most common form-zinc sulphate (also known as 'white vitriol')- is a metallic salt used as a wool mordant [38]. It is present in one pink [1], one red [3], several of the purple $(4,5,14,16,374,378$, $435,437,439,444)$ and some blue $(13,371,446)$ patterns.

Norwich dyers used river water, needed in great quantities for washing and rinsing, and water from other local sources. From at least the late thirteenth century Norwich's dye-works lined the banks of the slow flowing and meandering Wensum, a river containing chalk (calcium 

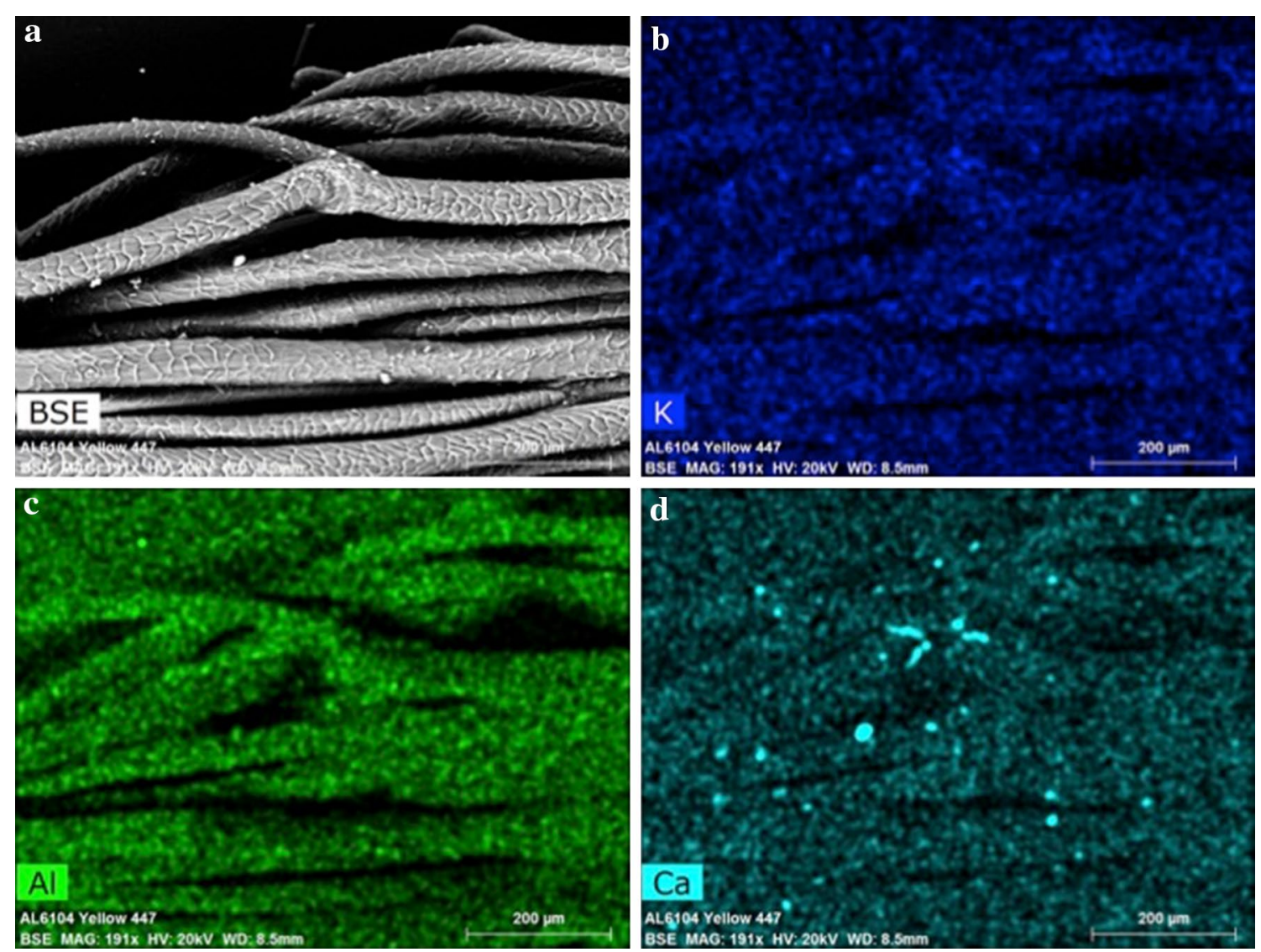

Fig. 3 SEM images of yellow from pattern 447, $191 \times$ magnification. a Back scattered electron image, b EDX false colour map showing potassium (K) distribution in the fibre, $\mathbf{c}$ EDX false colour map showing aluminium (Al) distribution in the fibre, $\mathbf{d}$ EDX false colour map showing calcium (Ca) distribution in the fibre

carbonate). In 1980, the dye-house manager Kenneth Ponting noted the crucial importance of water for dyeing, cleaning and disposing of waste. Hard water, he added, could be harmful when washing wool and cloth with soap, but could be advantageous in dissolving some dyes [39].

The presence of potassium could be associated either with the use of cream of tartar, or alum when the presence of potassium is above that which is related to smalt-containing paper. Alum, or potash alum $\left(\mathrm{KAl}\left(\mathrm{SO}_{4}\right)_{2} \cdot 12 \mathrm{H}_{2} \mathrm{O}\right)$, obtainable from Yorkshire in north-east England [40], was often used in conjunction with tartar [32]. The tartar was usually made up of potassium hydrogentartrate and calcium tartar, which would account for textiles with higher ratios of both calcium and potassium, such as pink in pattern 1, purple in 446 and yellows in 370, 372 and 447 (Table 1). SEM-EDX false colour X-ray maps of yellow 447 are displayed in Fig. 3, where the homogeneous distribution of aluminium and potassium in the fibre suggest the use of alum as mordant, whereas the inhomogeneous calcium distribution may point to hard-water or calcium-containing water, such as found in the River Wensum.

\section{Organic dyestuffs}

Newspaper advertisements recorded about two-thirds of the number of available dyestuffs indicated by Edmonds (some used as mordants as well): Spanish annatto, red sulphuret of arsenic (orpiment), indigo (East India, Spanish and paste), chemic (indigo in sulphuric acid), lac spirits (possibly Indian or other lac extract), madder, munjeet (Bengal madder), plum spirits (logwood mixed with tin mordant), citron bark (quercitron), safflower, woad, turmeric, sumac (Sicily and Malaga), the wood dyes barwood or camwood (African sandalwood), old fustic, logwood, peach wood and sanders (red sandalwood) [26, 27]. It was anticipated that the historical and experimental evidence would inform each other, thereby enhance, and expand our understanding of the dyestuffs used in Norwich to produce primary-reds, yellows, blues-and compound colours [7]. 


\section{Pinks and reds}

In the last decades of the eighteenth century, a handful of Norwich dyers, specialised in scarlet dyeing. The process was a separate branch of the industry because the dye could be easily tainted by accidentally mixing with other colours. Indeed, Norwich dyers found considerable fame in the early nineteenth century for their use of a rich, geranium-scarlet dye known as 'Norwich Red', a colour noted in some shawls held in private and museum collections [41].

We consistently found a combination of alizarin, purpurin, carminic and flavokermesic acid, and related compounds in all red and pink samples. The presence of carminic acid in all suggests the extensive use of expensive cochineal. All red and pink samples also contained significant amounts of tin and calcium, possibly suggesting the use of tin chloride and limewater. Ponting states that cochineal when mordanted in a solution of tin turned a brilliant scarlet with good light resistant qualities [39]. In addition, reds in patterns 3 and 10 and possibly pink 1 also contain madder (presence of alizarin, purpurin, and related red components).

Madder and cochineal were essential in providing dyers with the means to produce rich red colours. Cardon suggests madder was often prepared for wool dyeing with an alum mordant and red tartar, but aluminium is not detected using the experimental settings we used in our XRF instrument [32].

Dyer's madder (Rubia tinctorum), although native to the Middle East and the eastern Mediterranean region, was so adaptable that it was cultivated throughout Europe. It was grown in France and the Netherlands, with Dutch madder being considered the best [32]. England sourced most of its madder from Holland [42].

Attesting to its extensive use there are numerous seventeenth to early twentieth century European textiles in which cochineal and/or madder have been reported: Polish, Romanian, Scottish and Greek textiles have showed the presence of madder and/or cochineal. Cochineal was of Polish, Armenian and American origin, with cochineal from the Americas prevailing in most of the eighteenth century textiles and more recent textiles [29, 43-46].

Although cochineal could be collected or bought from Eastern Europe (Porphyrophora spp.), our experimental evidence suggested the source used was the Dactylopius coccus, an insect native to the Americas: patterns 1, 3, $10,15,367,443$ and 445 showed significant contents of carminic acid. Only on patterns 10 and 367 was flavokermesic acid detected in a relative percentage of about 1\%. This ruled out the use of Polish cochineal (Porphyrophora polonica) in which kermesic and flavokermesic acid content is between 12 and 38\% [15, 47]. Dye component dcII, present in Dactylopius coccus in $1.4-3.8 \%$ and in Porphyrophora polonica in $0.1-1.2 \%$, was also present in patterns 15 and 445 [47].

The absence of high contents of kermesic and flavokermesic acids in most of the samples would point to the use of Armenian or Mexican cochineal. However, since Armenian cochineal (Porphyrophora hamelii) had nearly replaced kermes as the main dyestuff used to produce scarlet by the eighteenth century, [32] it is more likely Norwich dyers used Mexican/South American true cochineal [32, 33, 47]. Cochineal grown in the Spanishdominated areas in Central and South America had to be imported through Spain before re-exportation to England. Although Norwich's manufacturers had extensive networks of contacts in Spain, the city's dyers almost certainly bought cochineal from London drysalters, or possibly from suppliers in Norwich.

\section{Yellows and orange}

A combination of luteolin and apigenin and their related components was found in most yellow threads (patterns $11,370,372)$ and both orange patterns $(7,440)$. In addition, morin and rutin were present in pattern 447 . Besides luteolin and apigenin, sulfuretin and ellagic acid were also detected in pattern 7 . There were no consistent results in the elements detected with XRF.

Most of the yellow samples (patterns 11, 370, 372, and 436) showed relatively high contents of lutelolin and apigenin, pointing to weld-dyed wool. Weld or dyer's rocket or dyer's weed (Reseda luteola), provided yellow, but possessed less tinctorial power than quercitron bark or fustic. Weld could be grown easily on rocky or poor soil and was often mixed with other dyes such as woad, indigo, and madder to give a variety of colours from green to muted browns like cinnamon [32, 39]. Its extensive use is evident through other scientific studies such as those carried out on Greek, Scottish and Romanian textiles, including ethnographic items, embroidery and carpets dating from the seventeenth to the nineteenth centuries $[23,29,44]$.

In contrast to most of the yellow-coloured samples, the one from pattern 447 showed morin, suggesting the use of old fustic (Maclura tinctoria), a strong yellow dye originally found in Central and South America and the Caribbean [32]. We were able to do SEM-EDX on this sample by carbon-coating the textile fibre. False colour maps (Fig. 3) show the presence of aluminium, calcium and potassium, strongly suggesting old fustic mordanted wool using calcium tartar possibly mixed with alum. Ponting notes yellows could be obtained using old fustic, aluminium and tin, although the resulting colours were not light fast [39]. Given the light sensitivity of flavonols such as morin, the vibrancy of the yellow hues in the pattern book examined gives additional weight to the view that 
the textile swatches have been rarely exposed to ultraviolet radiation $[23,29]$.

Only one sample-from pattern 7-contained weld. The presence of sulfuretin and fisetin strongly suggested the use of young fustic, which with the weld yields a rich orange hue. Young fustic (Cotinus coggygria), a shrub found in Southern and Central Europe provided a golden yellow colour, but it was often mixed with other dyestuffs to modify colours and/or hues. For instance, it was combined with cochineal from the Americas or weld to create more orange or olive tones [32]. Its leaves are also rich in tannins, which accounts for the presence of ellagic acid in the textile.

\section{Purples}

Lichen components related to orcein were identified in all purple-coloured samples except in patterns 374 and 439 where no dye components were detected. Samples from patterns 4, 435, 437, and 446 also contain indigotin, present in indigo plants or woad. In addition, possibly due to cross contamination, the sample from pattern 435 contained traces of morin, present in old fustic. Since we confirmed the presence of morin in numerous green samples, we believe its presence in purple 435 may be a result of contamination by handling of the pattern book after manufacture (for example, the yellow in pattern 447 on the same page contains morin). Finding indigo and/ or lichen components, such as orcein was expected: during the eighteenth century English dyers obtained their purples either by using blue and red dyes like indigo and madder, or from less colourfast lichens.

HPLC-PDA of the products of pure orcein (ACROS Organics $^{\mathrm{TM}}$, certified) undergoing mild hydrolysis allowed us to identify the three characteristic peaks and its corresponding UV-Vis spectra displayed in Fig. 4. All three characteristic components of hydrolysed orcein were identified in the samples from patterns $4,5,14,16,378$, 435, 437, 444 and 446, plus in blues 371 and 446 (Table 1).

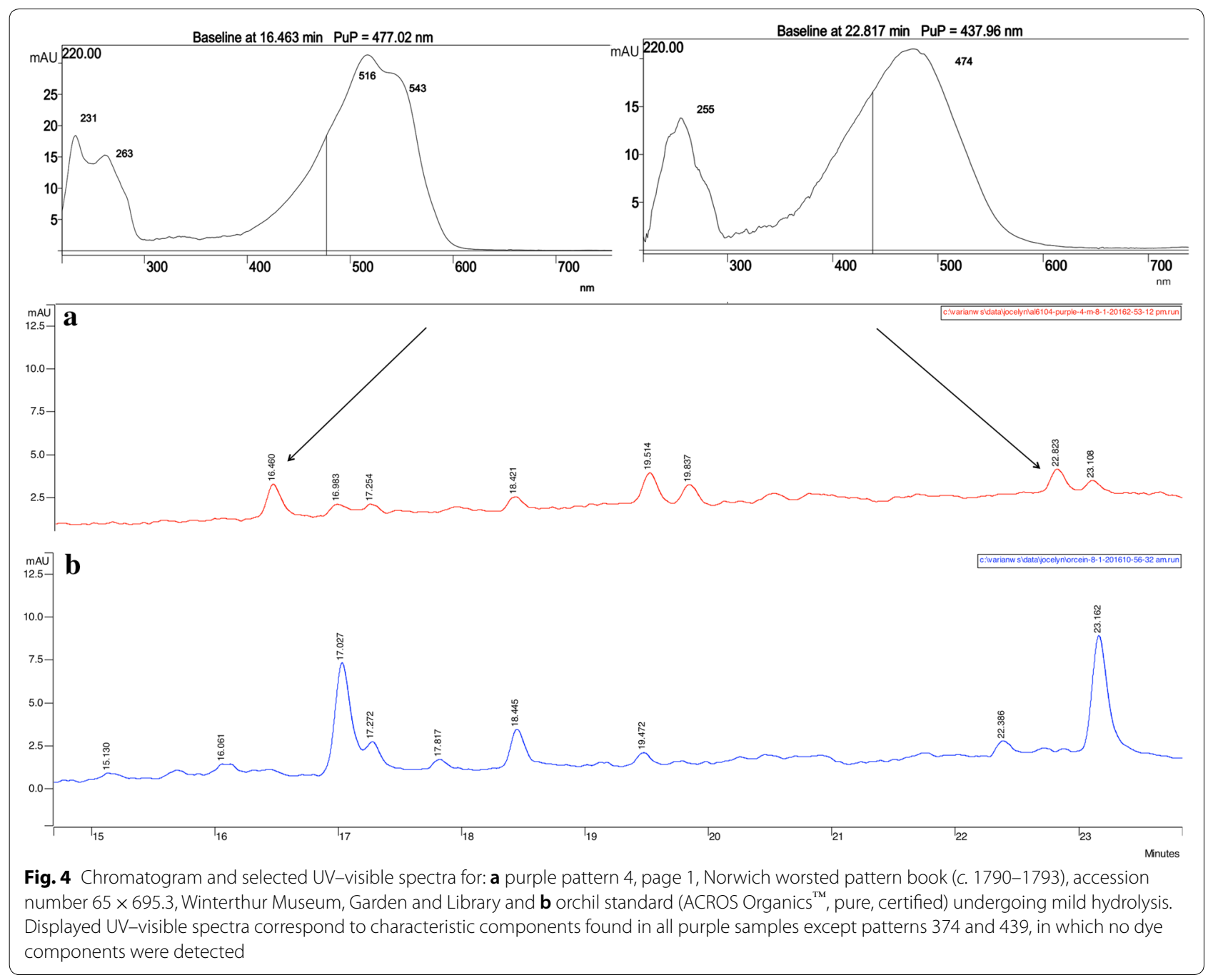


Orceins are among the chemical components found in lichens, evincing the extensive use of ochil, used as a dyestuff, including Roccella, Lecanora, Ochrolechia and Evernia $[33,48]$. Besides their use as substitute textile dyes for the precious Tyrian purple [33, 34, 49, 50], orchils have been used as food colourants and in cosmetics until the present day $[33,45$.

In their research on English dyes between 1775 and 1860, Mellor and Cardwell mention three lichen species, Rocella tinctoria, Rocella fuciformis, and Variolaria orcina, as examples of species used to produce orchil dyes. Rocella tinctoria could be found on the rocky cliffs along the coasts of the Mediterranean Sea, the Canary Islands, the Cape Verde Islands, Madeira, Morocco, the Azores, and along the western coast of Africa. Rocella fuciformis could also be found on the coast of the Mediterranean Sea as well as along the Atlantic coast as far as the English Channel [32]. Dyers in Norwich certainly used cudbear, patented in 1758 by George and Cuthbert Gordon of Leith, Scotland, for dyeing wool and silk a rich purple. The Norwich dyer Michael Stark played a part in its further development, advising the Glasgow dyer George Macintosh in his experiments with cudbear, using most notably Ochrolechia tartarea and various ingredients collected in the Highlands of Scotland [51, 52]. Manufacturers like Hall and Pentin in Heigham on the outskirts of Norwich produced cudbear during the 1820 s, but when they first started production is unknown [53]

A few scientific studies in which lichen dyes have been identified on textiles include: a Belgian sixteenth century tapestry; [54] a Hallstatt (Austria) archaeological textile fragment dated from 1400 to $400 \mathrm{BC}$; [31] fourteenth and fifteenth century liturgical paraments in medieval silk textiles at the National Museum in Gdansk, Poland [55] and in an assemblage of Anglo-Scandinavian and medieval textile fragments from Coppergate in York, England [56].

Lastly, we could not identify any dye components in samples from patterns 374 and 439. Since iron and calcium were present in significant ratios as well as zinc and copper as minor components, it is a possibility that dye concentration was below detection limits or perhaps the dyer used a mineral dye.

\section{Browns}

High contents of iron and/or copper were found in most of the brown samples. The use of such salts, according to Cardon, being consistent with darkening colours [32]. Browns in patterns 9 and 376 displayed a variety of dye components including quercetin, small amounts of indigo -related components (identified only after harsh hydrolysis. The sample from pattern 438 showed a variety of tannins, ellagic acid included. As a group, and in contrast to our study of Viennese textiles from the same time period, these browns appeared to be manufactured with well-defined recipes [57].

\section{Blues}

No dye components could be unequivocally identified in most blue samples after mild hydrolysis. Suspecting inefficient extraction, a harsh hydrolysis method was performed on the same sample (Table 1). XRF did not show any consistent elemental composition across samples. It is possible all elements detected came from vats used by the dyers, since indigo does not require a mordant to dye $[32,33,48]$. The use of indigo plants as a source for blue colouring is consistent with analyses carried out on other eighteenth century European textiles [29, 43, 58].

Except for the sample from pattern 443, where no dye components were identified after both mild and harsh hydrolyses, all samples showed the presence of indigotin. In addition, lighter blue samples also contained indirubin (patterns 436 and 440). Besides indigotin and possible cross contamination, light and dark blue samples from two camblets (patterns 371and 446) also showed one of the characteristic dye components of hydrolysed orchil $\left(\mathrm{t}_{\mathrm{R}} 17 \mathrm{~min}, \lambda_{\max } 588 \mathrm{~nm}\right.$ ) shown in Additional file 1 . Indigotin-containing plants (Indigofera) were widely used for dyeing during the eighteenth century with most of them being sourced from North America, where it had been introduced to the south in the late seventeenth century, and the Caribbean [59].

Before the introduction of indigo, woad (Isatis tinctoria) was the only dye for blue colours, from light to dark, and therefore in great demand. Besides indigo being used to strengthen it, woad was used in combination with weld to produce green and with madder to make black and as a ground for indigo [39, 60].

\section{Greens}

The dyestuffs found in the green swatches are overall consistent. Identification of indigotin agrees with historical research, which suggests that shades of green were achieved by first dyeing the wool with indigo or woad to create a blue ground and then dyeing again using yellow dyes like weld [32.] A study by Karapanagiotis of Greek garments dating from early eighteenth century supports this method $[58,61]$. Interestingly, weld was not present in any of the green samples we tested.

Instead, quercetin was detected at $14.6 \mathrm{~min}$ on samples in patterns 2,12 , and 377, where XRF revealed an approximate $1: 2 \mathrm{Cu}: \mathrm{Fe}$ ratio. The presence of quercetin indicated the use of a quercitron, obtained from the bark of the Eastern Black Oak (Quercus velutina), native to North America. Edward Bancroft originally discovered 
quercitron dye in 1771 and received a British patent for it in 1779, which expired 20 years later [62]. The Norwich dyer Michael Stark had greatly assisted Bancroft in his experiments through their correspondence. Stark is said to have the first in Britain to successfully use the quercitron dye 'on an extensive scale' [63]. Heather Hansen's reference to the use of iron with quercitron to create an olive green is consistent with our observations [62].

The presence of copper in relation to green textiles where morin was identified matches historical information that points to the use of copper mordants with old fustic to create olive tones [64]. Morin was identified on samples from patterns $367,368,370$ and 377 , which indeed points to the use of old fustic, a 'New World' dyestuff. Besides morin, we also identified quercetin in pattern 377 , which strongly suggests a compound recipe.

XRF revealed pattern 442 is copper- (and not iron-) rich; no yellow components were identified, albeit indigotin was present. Perhaps the yellow components' concentration fell out of the instrument's detection limits, but given the trend we observed, it seems reasonable to associate this green 442 with old fustic greens.

Lastly, in the dark green in the sample from 372, where iron was the main element detected, neither yellow nor blue dye components were observed. The sample allowed for four analyses (all using a mild and a harsh hydrolysis method), none of which exhibited dye components. This strongly suggests the use of an iron-containing mineral, such as iron sulphate, and not an organic dye.

\section{Glaze and adhesive}

Page 1 (Fig. 1a) of the book features the above-mentioned glazed and striped callimanco swatches. The coating adds a distinctive, even glossy sheen to the textile, which emphasises the multiple colours. Contemporary reports describe the technique of applying the glaze by hotpressing, but the substance used to create the glossy surface remains unknown. To our knowledge, Beth Szuhay was the first person to pursue identification of this glazing substance as part of her independent study 'Developing a Protocol for Analysis of Textile Finishes on Wool' in 2000. By visual examination, scientific analysis and historical research she aimed to 'develop a protocol for identification of the chemical components of textile finishes through analytical means.' [9] Her spot tests and FTIR suggested the presence of a gum, and she acknowledged the need for 'other confirmation techniques'. In our case, all FTIR spectra of water-soluble extracts of glazed samples showed two strong, broad bands, centred at around 1080 and $3300 \mathrm{~cm}^{-1}$ due to $\mathrm{C}-\mathrm{O}$ and $\mathrm{O}-\mathrm{H}$ groups, respectively. A third characteristic band centred at approximately $1620 \mathrm{~cm}^{-1}$, evinces intermolecular hydrogen bonds of water to a carboxyl group [65]. Altogether, these spectra strongly indicated the presence of a natural gum (Additional file 1 shows FTIR spectra). Subsequent extraction with chloroform suggested no non-polar components were present in the glaze.

So far, only two gums available to Norwich dyers have been identified in newspaper advertisements: 'gum Senega Arabic' and 'gum tragacanth' [66]. Besides performing FTIR analysis with each of the individual sixteen extracts, we used a combination of them all to run GCMS, which still rendered a relatively small sample, allowing us to do just one analysis, likely contaminated with glucose from samples being adhered to a paper support. Because glucose as contamination is common in historic and ancient artefacts, running a sample of a nearby area as blank is highly recommended $[67,68]$. However, given our pattern book is practically undamaged, we considered taking another sample unethical and did not run this blank. Our analysis showed major peaks for glucose and galactose, and minor peaks for arabinose and rhamnose. Altogether this evidence might suggest the presence of a polysaccharide, perhaps a natural gum suggested by FTIR and mentioned in advertisements. Its presence could not be confirmed or unequivocally identified. This is ongoing research. Using a different pattern book, held in Special Collections at the Winterthur Museum, we have collected glazed samples, from which water- and carbon tetrachloride- soluble components will be analysed for a larger study on the subject (unpublished results).

Kerridge states that callimanco, especially if not used for men's wear, was often glazed by a coating of beeswax [60]. Priestley, in her description of callimancoes, states that the fabric 'was usually glossed by hot-pressing to accentuate the bright colours, and even sometimes coated with beeswax' [1]. In two of the samples from page 1 weak and sharp split bands around $730 \mathrm{~cm}^{-1}$ suggested the presence of wax besides gum. However, it is very likely that cross-contamination due to handling over the years happened, hence neither proving nor disproving Kerridge's or Priestley's observations.

Finally, FTIR analysis of the yellowed adhesive used to stick down the swatches suggested the presence of a natural gum, displaying the same pattern described for the glaze's results. We did not characterise this material using any complementary technique because the textiles were our main focus.

\section{Conclusions}

Scientific research relating to the Norwich dyeing industry in the late eighteenth and early nineteenth centuries is scarce. Although there is a growing body of information concerning dyers, the corresponding understanding of dyeing practices remains minimal. In a similar way, in spite of some documentary evidence describing the 
glazing practices and methods of hotpressers, no definitive record of the constituents of the glazes has been found.

We limited our case study to 47 out of 685 samples for ethical considerations, and used a combination of spectroscopic, microscopic and chromatographic techniques to identify dyes and infer the presence of mordants. In conjunction with archival research, these scientific results were successfully cross-referenced with documentary sources. Weld, young and old fustic, quercitron, cochineal, madder, indigo plants and orchil dyes were all found in the samples (weft) in repetitive combinations that suggested well-defined recipes. In turn, these results advanced our knowledge of the substances used to produce primary and compound colours. Furthermore, we found scientific evidence that points the presence of a water-soluble glaze material, likely a natural gum.

During this initial stage of an ongoing research project, we have also made progress in one of our main goals: contributing to the understanding of these materials as an avenue to ensuring their preservation. While destructive analysis such as HPLC-PDA-MS is often conclusive and commonly used to assess collections, it is not sustainable in a museum or archival environment, where instrumental analysis is often limited, if available at all. By studying dated and well-preserved textiles, such as those presented in our case study, we are providing evidence that we anticipate will help in the management and care of collections. For instance, the presence of light sensitive dyes such as flavonoid- containing yellow and green (quercitron, weld, young and old fustic), and especially purple (orchil) textiles, needs to be taken into consideration when deciding display and storage conditions where light levels should be kept at their lowest. Our findings showed J. Tuthill \& Sons dyers used recipes/combinations consistently and repetitively. This poses a question of whether the lack of recipe books is indeed due to the 'secrecy' Mellor and Cardwell suggest [5], or if it is related to the 'slow start of publications' that Kirby, et. al. attribute to the English wool having been dyed for so long in Flanders and Holland [69]. Because of the consistent and repetitive use of combinations, certain colours and patterns likely contain a dye combination, which can be translated into informed guesses of the presence of certain chromophores therein. These informed guesses, in turn, could allow for collections' assessment even in the absence of scientific dye analysis. Further, the presence of what seems to be water-sensitive materials such as a gum used for surface glazing imposes the need for stable and mid-level relative humidity conditions, to avoid either the drying or softening of the coating. In presenting our earliest results, we trust our findings can contribute to the care of these beautiful and important textiles in both swatch form and in costumes and furnishing collections.

\section{Additional file}

Additional file 1. Experimental Details and Instrumentation.

\section{Abbreviations}

XRF: X-ray fluorescence; FTIR: Fourier transform infrared spectroscopy; SEMEDX: scanning electron microscopy-energy dispersive X-ray spectroscopy; GCMS: gas chromatography-mass spectrometry; HPLC-PDA: high performance liquid chromatography-photodiode array detector.

\section{Authors' contributions}

JAG leads this project, collected (or supervised the collection) and interpreted all scientific data, contextualized historic references and edited the final version of the manuscript. MN conducted all historic research and edited crossreferencing of historic and scientific data. Both authors read and approved the final manuscript.

\section{Author details}

${ }^{1}$ Department of Art Conservation, University of Delaware, 18 E. Main St. Room 303, Newark, DE 19716, USA. ${ }^{2}$ Independent Researcher of Norwich's Textiles Industry and Trade Between 1750 and 1840, Salhouse, Norwich, England, UK.

\section{Acknowledgements}

Undergraduate Research Program, University of Delaware. Very special thanks to Linda Eaton, Jeanne Solensky and Laura Parrish for facilitating the study of these fabrics, and to Dr.Vicki Cassman, Catherine Matsen, Ann Nix, Cathy Terry and Helen Hoyte for their assistance. Thanks to Dr. Chris Petersen for performing GC-MS analysis, Dr. Judy Rudolph for SEM-EDX analysis and Jim Schneck for photography. We are also deeply grateful to each and every reader and reviewer, for their insight, comments and suggestions.

\section{Competing interests}

The authors declare that they have no competing interests.

\section{Availability of data and materials}

All Experimental Details (instrumentation and methods), FTIR spectrum of glaze extract, and UV-Vis spectrum of hydrolysed orchil are in additional file. All other data can be available from the corresponding author on reasonable request.

\section{Funding}

The authors are grateful to the Undergraduate Research Program of the University of Delaware and their 2016 Summer Scholars Program for supporting Taylor Pearlstein, who ran many of the samples discussed here.

\section{Publisher's Note}

Springer Nature remains neutral with regard to jurisdictional claims in published maps and institutional affiliations.

Received: 4 October 2018 Accepted: 19 December 2018

Published online: 24 December 2018

\section{References}

1. Priestley U. The fabric of stuffs: The Norwich textile industry from 1565. Norwich: University of East Anglia, Norwich: Centre of East Anglian Studies; 1990. p. 7-44.

2. Sykas PA. The secret life of textiles: six pattern book archives in North West England: Bolton Museum, Art Gallery \& Aquarium; 2005.

3. Winterthur Library. Wintercat-Norwich pattern books. 2018. https:// goo.gl/k9uqnz 
4. James J. History of the worsted manufacture in England; from the earliest times with introductory notices of the manufacture among the ancient nations and during the Middle Ages. Bradford: England; 1857.

5. Mellor CM, Cardwell DSL. Dyes and dyeing 1775-1860. Br J Hist Sci. 1963;1(3):265-79.

6. Scarfe N, Wilson R. Norwich's textile industry in 1784, observed by Maximilien de Lazowski. Text Hist. 1991;23(1):114.

7. Edmonds $\mathrm{JH}$. The history and practice of eighteenth century dyeing. Little Chalfont: John Edmonds; 1999. p. 18-49.

8. Edmonds $\mathrm{JH}$. Textile dyeing through the ages. J Ethnol Stud. 2003;42(1):61-72.

9. Szuhay B. Developing a Protocol for Analysis of Textile Finishes on Wool. Independent Study. Winterthur, DE: Winterthur/University of Delaware Program in Art Conservation; 2000.

10. Wouters J, Alcantara-Garcia J. Norwich Textile. Accession number 1959.95.3. (AL6074). Winterthur Museum; 2015.

11. Norfolk Museums Service. Norwich pattern cards: accession number: NWHCM 1953.73.1-5; 2018. https://goo.gl/QncVCE.

12. Colombini MP, Andreotti A, Baraldi C, Degano I, Łucejko JJ. Colour fading in textiles: a model study on the decomposition of natural dyes. Microchem J. 2007;85(1):174-82.

13. Manhita A, Santos V, Vargas H, Candeias AJ, Ferreira T, Dias CB. Ageing of brazilwood dye in wool - a chromatographic and spectrometric study. J Cult Herit. 2013;14(6):471-9.

14. Wouters J, Grzywacz CM, Claro A. Markers of identification of faded safflower (Carthamus tinctorius L.) colorants by HPLC-PDA-MS. Stud Conserv. 2010;55:186-203.

15. Wouters J, Verhecken A. The coccid insect dyes: HPLC and computerized diode-array analysis of dyed yarns. Stud Conserv. 1989;34(4):189-200.

16. Poulin J. A New methodology for the characterisation of natural dyes on museum objects using gas chromatography-mass spectrometry. Stud Conserv. 2018;63:36-61.

17. Domenech-Carbo A, Domenech-Carbo MT, Sauri-Peris MC. Electrochemical identification of flavonoid dyes in solid work of art samples by abrasive voltammetry at paraffin-impregnated graphite electrodes. Talanta. 2005;66(3):769-82.

18. Maynez-Rojas MA, Casanova-Gonzalez E, Ruvalcaba-Sil JL. Identification of natural red and purple dyes on textiles by fiber-optics reflectance spectroscopy. Spectrochim Acta Part A Mol Biomol Spectrosc. 2017; 178:239-50.

19. Gulmini M, Idone A, Diana E, Gastaldi D, Vaudan D, Aceto M. Identification of dyestuffs in historical textiles: strong and weak points of a non-invasive approach. Dyes Pigm. 2013;98(1):136-45.

20. Jurasekova Z, Domingo C, Garcia-Ramos JV, Sanchez-Cortes S. In situ detection of flavonoids in weld-dyed wool and silk textiles by surfaceenhanced Raman scattering. J Raman Spectrosc. 2008;39(10):1309-12.

21. Leona M, Stenger J, Ferloni E. Application of surface-enhanced Raman scattering techniques to the ultrasensitive identification of natural dyes in works of art. J Raman Spectrosc. 2006;37:981-92.

22. Pozzi F, Leona M. Surface-enhanced Raman spectroscopy in art and archaeology. J Raman Spectrosc. 2016;47:67-77.

23. Ferreira ESB, Quye A, Hulme AN, McNab H. LC-Ion Trap MS and PDAHPLC-complementary techniques in the analysis of flavonoid dyes in historical textiles: the case study of an 18th-century herald's tabard. Dyes Hist Archaeol. 2003;19:13-8.

24. Ferreira ES, Hulme AN, McNab H, Quye A. The natural constituents of historical textile dyes. Chem Soc Rev. 2004;33(6):329-36.

25. Wouters J, Grzywacz CM, Claro A. A comparative investigation of hydrolysis methods to analyze natural organic dyes by HPLC-PDA — nine methods, twelve biological sources, ten dye classes, dyed yarns, pigments and paints. Stud Conserv. 2011;56(3):231-49.

26. Norwich Mercury. 7 October 1826; 24 October 1829; 15 January, 22 October 1831.

27. Norfolk Chronicle. 31 May 1817; 25 September 1819; 25 March, 7 October 1826; 24 October 1829; 15 January, 22 October 1831; 2 December 1837.

28. Fairlie S. Dyestuffs in the eighteenth century. Econ Hist Rev. 1965;17(3):488-510.

29. Manhita A, Balcaen L, Vanhaecke F, Ferreira T, Candeias AJ, Dias CB. Unveiling the colour palette of Arraiolos carpets: material study of carpets from the 17th to 19th century period by HPLC-DAD-MS and ICP-MS. J Cult Herit. 2014;15(3):292-9.
30. Trojanowicz M, Orska-Gawrys J, Surowiec I, Szostek B, Urbaniak-Walczac K, Kehl J, et al. Chromatographic investigation of dyes from Coptic textiles from the National Museum in Warsaw. Stud Conserv. 2004;49(2):115-30.

31. Joosten I, van Bommel MR, Keijzer RH, Reschreiter H. Micro analysis on Hallstatt textiles: colour and condition. Microchimica Acta. 2006;155(1-2):169-74.

32. Cardon D. Natural dyes: sources, tradition, technology and science. London: Archetype Books; 2007. p. 500.

33. Graaff JH. The colourful past. Origins, chemistry and identification of natural dyestuffs. Italy: Archetype Publications; 2004.

34. Cardon D. The dyer's handbook: memoirs of an 18th-century master colourist. United Kingdom: Oxbow Books; 2016.

35. Eastaugh N, Walsh V, Chaplin T, Siddal R. Pigment compendium: a dictionary and optical microscopy of historical pigments. Oxford: ButterworthHeinemann; 2008. p. 958.

36. Partridge WA. A practical treatise on dying woollen, cotton, and skein silk, the manufacturing of broadcloth and cassimere. New York: Wallis \& Co; 1823.

37. Kolar J, Strlič M. Iron gall inks: on manufacture, characterization, degradation and stabilization. Ljubljana: National and University Library; 2006. p. 253.

38. Gardner WM. Mordanting Wool. Textile Colorist. XVIII. XVIII (Philadelphia)1896. p. 297.

39. Ponting KG. A dictionary of dyes and dyeing. London: Bell \& Hyman; 1980

40. Miller I. Steeped in history. The alum industry of North-east Yorkshire. Yorkshire: North York Moors National Park Authority; 2002.

41. Hoyte HM. The dyers and printers of Norwich. In: Clabburn P, editor. The Norwich shawl: its history and a catalogue of the collection at Strangers Hall Museum, Norwich. London: HMSO; 1995. p. 47.

42. Low D. Elements of practical agriculture, comprehending the cultivation of plants, the husbandry of the domestic animals, and the economy of the farm. London: Longman; 1838. p. 357.

43. Petroviciu I, Vanden Berghe I, Cretu I, Albu F, Medvedovici A. Identification of natural dyes in historical textiles from Romanian collections by LC-DAD and LC-MS (single stage and tandem MS). J Cult Herit. 2012;13(1):89-97.

44. Surowiec I, Quye A, Trojanowicz M. Liquid chromatography determination of natural dyes in extracts from historical Scottish textiles excavated from peat bogs. J Chromatogr A. 2006;1112(1-2):209-17.

45. Aceto M, Arrais A, Marsano F, Agostino A, Fenoglio G, Idone A, et al. A diagnostic study on folium and orchil dyes with non-invasive and microdestructive methods. Spectrochim Acta Part A Mol Biomol Spectrosc. 2015;142:159-68

46. Lech K, Jarosz M. Identification of Polish cochineal (Porphyrophora polonica L.) in historical textiles by high-performance liquid chromatography coupled with spectrophotometric and tandem mass spectrometric detection. Analy Bioanalyt Chem. 2016;408(12):3349-58.

47. Rosenberg E. Characterisation of historical organic dyestuffs by liquid chromatography-mass spectrometry. Anal Bioanal Chem. 2008;391(1):33-57.

48. Bechtold T, Mussak R. Handbook on natural colorants. Stevens CV, editor. Great Britain: Wiley; 2009.

49. Whitworth I, Koren ZC. Orchil and Tyrian purple: two centuries of Bedfords from Leeds. Ambix. 2016;63(3):244-67.

50. Kok A. A short history of the orchil dyes. Lichenologist. 1966;3:248-72.

51. The sessional papers printed by order of the House of Lords, reports of the Commissioners, hand-loom weavers: Hearing before the Vol XXXVII: 307 (Parliamentary Papers 1840).

52. Gordon G, Gordon C. The cudbear manufactory: December 12, 2018; 1758. https://goo.gl/iRQ9Jd.

53. Norfolk Chronicle. 10 November 1827

54. Doherty B, Gabrieli F, Clementi C, Cardon D, Sgamellotti A, Brunetti B, et al. Surface enhanced Raman spectroscopic investigation of orchil dyed wool from Roccella tinctoria and Lasallia pustulata. J Raman Spectrosc. 2014;45(9):723-9.

55. Witkowski B, Ganeczko M, Hryszko H, Stachurska M, Gierczak T, Biesaga M. Identification of orcein and selected natural dyes in 14th and 15th century liturgical paraments with high-performance liquid chromatography coupled to the electrospray ionization tandem mass spectrometry (HPLC-ESI/MS/MS). Microchem J. 2017;133:370-9.

56. Walton P. Textiles, cordage and raw fibre from 16-22 Coppergate. 2013 ed1989. 
57. Thomas R, Alcántara-García J, Wouters J. A snapshot of Viennese textile history using multi-Instrumental analysis: benedict codecasa's swatchbook. MRS Adv. 2017;2(63):3959-71.

58. Karapanagiotis I, Lakka A, Valianou L, Chryssoulakis Y. High-performance liquid chromatographic determination of colouring matters in historical garments from the Holy Mountain of Athos. Microchim Acta. 2007;160(4):477-83.

59. Phipps E. Global colours. In: Peck A, editor. Interwoven globe The worldwide textile trade, 1500-1800 New York. USA: Metropolitan Museum of Art; 2013. p. 124-5.

60. Kerridge E. Textile manufactures in early modern England. Manchester: Manchester University Press; 1985. p. 51-2.

61. Karapanagiotis I, Mantzouris D, Kamaterou P, Lampakis D, Panayiotou C. Identification of materials in post-Byzantine textiles from Mount Athos. $J$ Archaeol Sci. 2011;38(12):3217-23.

62. Hansen HN. The quest for quercitron. Revealing the story of a forgotten dye. Winterthur: Universtity of Delaware; 2011.

63. Norfolk Chronicle. 26 February 1831
64. "OurTextileSchool". Our textile school for dyers. America's textile reporter: for the combined textile industries American wool and cotton reporter. 1902.

65. Derrick MR, Stulik D, Landry JM. Infrared spectroscopy in conservation science. Los Angeles: The Getty Conservation Institute; 1999. p. 235

66. Norfolk Chronicle. 18 October 1828.

67. Lluveras-Tenorio A, Mazurek J, Restivo A, Colombini MP, Bonaduce I. The development of a new analytical model for the identification of saccharide binders in paint samples. PLoS ONE. 2012;7(11):e49383.

68. Lluveras-Tenorio A, Mazurek J, Restivo A, Colombini MP, Bonaduce I. Analysis of plant gums and saccharide materials in paint samples: comparison of GC-MS analytical procedures and databases. Chem Cent J. 2012;6(115):1-16.

69. Kirby J, van Bommel M, Verhecken A. Natural colorants for dyeing and lake pigments Practical recipes and their historical sources. London: Archetype Publications; 2014.

\section{Submit your manuscript to a SpringerOpen ${ }^{\odot}$ journal and benefit from:}

- Convenient online submission

- Rigorous peer review

- Open access: articles freely available online

- High visibility within the field

- Retaining the copyright to your article

Submit your next manuscript at $\boldsymbol{\nabla}$ springeropen.com 